\title{
Revisiting Late-Onset Asthma: Clinical Characteristics and Association with Allergy
}

This article was published in the following Dove Press journal:

Journal of Asthma and Allergy

\author{
Santiago Quirce (1D) \\ Enrico Heffler ${ }^{2}$ \\ Natalia Nenasheva ${ }^{3}{ }^{3}$ \\ Pascal Demoly (D) \\ Andrew Menzies-Gow ${ }^{5}$ \\ Ana Moreira-Jorge ${ }^{6}$ \\ Francis Nissen ${ }^{7}$ \\ Nicola A Hanania ${ }^{8}$ \\ 'Department of Allergy, La Paz University \\ Hospital, IdiPAZ and Universidad \\ Autónoma de Madrid, Madrid, Spain; \\ ${ }^{2}$ Personalized Medicine, Asthma and \\ Allergy, Humanitas Clinical and Research \\ Center, IRCCS, Rozzano, MI, Italy; \\ ${ }^{3}$ Department of Allergology and \\ Immunology of Russian Medical Academy \\ for Continuous Medical Education, \\ Moscow, Russian Federation; \\ ${ }^{4}$ Department of Pulmonology, Division of \\ Allergy, Hôpital Arnaud de Villeneuve, \\ University Hospital of Montpellier, \\ Montpellier, France; ${ }^{5}$ Department of \\ Respiratory Medicine, Royal Brompton \\ Hospital, London, UK; ${ }^{6}$ Novartis \\ Farmaceutica, S.A., Barcelona, Spain; \\ ${ }^{7}$ London School of Hygiene and Tropical \\ Medicine, London, UK; ${ }^{8}$ Section of \\ Pulmonary and Critical Care Medicine, \\ Baylor College of Medicine, Houston, \\ TX, USA
}

Correspondence: Santiago Quirce Hospital Universitario La Paz, P. La Castellana, 26I, Madrid, 28046 Spain Email squirce@gmail.com

\begin{abstract}
The Global Initiative for Asthma (GINA) 2020 defines late-onset asthma (LOA) as one of the clinical phenotypes of asthma wherein patients, particularly women, present with asthma for the first time in adult life, tend to be non-allergic and often require higher doses of inhaled corticosteroids (ICS) or are relatively refractory to corticosteroid treatment. In this review, we examine the published literature improve the understanding of the following aspects of LOA: 1) the age cut-off for its diagnosis; 2) its distinct clinical phenotypes, characteristics and risk factors; and 3) its association with allergic comorbidities and conditions. Overall, our review reveals that clinicians and researchers have used multiple age cut-offs to define LOA, with cut-off ages ranging from $>12$ years to $\geq 65$ years. LOA has also been classified into several distinct phenotypes, some of which drastically differ in their clinical characteristics, course and prognosis. Although LOA has traditionally been considered non-allergic in nature, our review indicates that it is commonly associated with allergic features and comorbidities. Our findings suggest that there is an urgent need for the development of more clear clinical practice guidelines that can provide more clarity on the definition and other aspects of LOA. In addition, the association of LOA and allergy needs to be re-examined to frame a more optimal treatment strategy for patients with LOA.
\end{abstract}

Keywords: asthma, diagnosis, age of onset, allergy, allergic asthma, asthma phenotypes

\section{Introduction}

Asthma is a chronic inflammatory respiratory disease affecting approximately 339 million people worldwide. ${ }^{1}$ It is characterized by symptoms of wheezing, shortness of breath, chest tightness and cough that vary over time and in intensity. ${ }^{2}$ Age of onset of asthma plays an important role in predicting the clinical course and management of this disease. ${ }^{3}$ Although asthma often begins in childhood, asthma symptoms can occur at any time during life and some patients experience symptoms for the first time at a later stage in life. ${ }^{4,5}$

For more than half a century, clinicians and researchers have been trying to devise an appropriate classification to differentiate adult-onset and childhood-onset asthma. In 1947, Rackeman classified asthma based on its age of onset into "extrinsic" asthma (onset before the age of 30 years) and "intrinsic" asthma (onset after the age of 40 years). ${ }^{6}$ The official European Academy of Allergy and Clinical Immunology (EAACI) position statement in 2001 modified this terminology further. The terms "extrinsic" and "intrinsic" asthma were replaced by "allergic" and "non-allergic" asthma, respectively. ${ }^{7}$ In 2004, Miranda et al introduced the terms "early-onset asthma" and "late-onset asthma" (LOA) to differentiate asthma based on age of onset. ${ }^{8}$ 
The 2020 version of the GINA strategy defines LOA as one of the clinical phenotypes of asthma wherein patients, particularly women, present with asthma for the first time in adult life, tend to be non-allergic and often require higher doses of inhaled corticosteroids (ICS) or are relatively refractory to corticosteroid treatment. ${ }^{2}$ A closer look at this definition reveals that many questions about this condition remain unanswered. A better understanding of all the aspects of LOA can help clinicians make more precise guided treatment decisions using existing or new treatment approaches and to devise optimal personalized management of the disease.

In this review, we examine published literature in an attempt to answer the questions on a) the age cut-off for the diagnosis of LOA; b) its distinct clinical phenotypes, characteristics and risk factors; c) its association with allergy and allergic comorbidities.

\section{Methods}

We conducted a literature search using EMBASE for literature between 1996 and May 2020 using the search terms "allergic asthma", "atopic asthma" "late onset", "adult onset", "asthma". Potentially relevant publications and registries were manually screened and reviewed and non-relevant publications were excluded on the basis of pre-determined criteria such as excluding editorials, opinion pieces, articles without the full text available, and articles without authors.

\section{Defining the Age Cut-off for LOA}

While the latest GINA strategy clarifies that asthma occurs for the first time in adult life in patients with LOA, it fails to define the exact age that can be considered as a cut-off to confirm the diagnosis of LOA. ${ }^{2}$ We examined the published literature to understand how researchers and clinicians are defining the age cut-offs for LOA. Table 1 summarizes the different age cut-offs used in the publications we examined $(n=18)$, which we shortlisted from our literature search.

Several parallel schools of thought seem to exist about the age cut-off for LOA. Genetic variants have been distinctly associated with asthma that sets at $12-16$ years of age. ${ }^{9,10}$ While some researchers have considered retirement age ( $\geq 65$ years) as an appropriate cut-off for LOA, other researchers have defined LOA as asthma with onset after the end of childhood (12/16/18 years). Yet, other researchers have reported middle age (30 or 40 years) to be appropriate as the cut-off age for the diagnosis of LOA.
Table I Summary of Different Cut-Offs for Late-Onset Asthma

\begin{tabular}{|c|c|}
\hline Cut-Off Age & Study (Year) \\
\hline 12 years & $\begin{array}{l}\text { Wu et al }(2016)^{12} \\
\text { Miranda }(2004)^{8} \\
\text { Holguin et al }(2011)^{13} \\
\text { Bhaskar et al }(2013)^{14}\end{array}$ \\
\hline 16 years & $\begin{array}{l}\text { Toren et al }(1999)^{15} \\
\text { Jarvis et al }(2012)^{16}\end{array}$ \\
\hline 18 years & $\begin{array}{l}\text { Sood et al }(2013)^{17} \\
\text { Chaudhuri et al }(2016)^{18} \\
\text { Schwindt et al }(2010)^{19}\end{array}$ \\
\hline 20 years & Bedolla-Barajas et al $(2015)^{20}$ \\
\hline 30 years & Nenasheva et al $(2019)^{30}$ \\
\hline 40 years & $\begin{array}{l}\text { Maio et al }(2018)^{21} \\
\text { Heffler et al }(2019)^{22}\end{array}$ \\
\hline $13-50$ years & Wu et al $(2015)^{23}$ \\
\hline $64 / 65$ years & $\begin{array}{l}\text { Bauer et al }(1997)^{24} \\
\text { Gillman et al }(2012)^{25} \\
\text { Ariano et al }(2012)^{26} \\
\text { Gibson et al }(2010)^{27}\end{array}$ \\
\hline
\end{tabular}

From these articles, it is quite evident that there is a lack of consensus amongst researchers and clinicians about the exact cut-off age for LOA.

It is important to note that clinical characteristics of LOA can manifest differently at different age cut-offs of LOA. For example, there has been epidemiological evidence to distinguish very late-onset asthma (defined as age-of onset at 60 years or older) from "classical" lateonset asthma (defined as age-of-onset at 12 years or older), eg, female predominance disappeared with increasing age, which was also modified by allergic status. ${ }^{11}$

\section{Epidemiology of LOA}

The inconsistency in defining LOA is one reason why the exact disease burden of LOA has not been adequately defined. The epidemiology of LOA has been assessed in several population-based studies in Europe. The HELIUS study examining six ethnic groups in the Netherlands (Dutch, South-Asian Surinamese, African Surinamese, Moroccan, and Turkish and Ghanaian origin) and evaluating 23,356 participants, demonstrated a prevalence of LOA (age cut-off $\geq 18$ years) ranging from $2.4 \%$ to $6.0 \%$ in these populations. ${ }^{28}$ A Swedish population-based study in 15,813 adults revealed that the incidence rate of LOA 
(age cut-off $\geq 16$ years) amongst males and females was 1.0/1000 person-years and 1.3 cases/1000 person-years, respectively. Furthermore, the incidence rate was reported to be high (3.0 cases/1000 person-years) in females aged 16-20 years. ${ }^{15}$ The Global Allergy and Asthma Network of Excellence (GA(2)LEN) survey in Europe conducted in 52,000 adults found an overall asthma prevalence rate of $8.5 \%$, of which $49.5 \%$ reported an age of onset after the age of 16 years. $^{16}$ A 2-year population-based study showed an annual incidence of LOA (no clear age cutoff given) rate of 160/100,000 per year. ${ }^{29}$ Of the 439 patients with asthma analyzed in an Italian web-based registry, 30\% reported LOA (age cut-off $>40$ years) symptoms and adult diagnosis. ${ }^{21}$

Similar epidemiological data for LOA are also available for other geographies. A population-based study from Taiwan demonstrated the prevalence of physiciandiagnosed LOA (age cut-off $\geq 12$ years) to be $2.1 \%$ (449/ $21,057)$ in the study population. ${ }^{23}$ The age- and sexadjusted incidence of LOA (age cut-off $>65$ years) in population-based study from Rochester, Minnesota in the US was reported to be $95 / 100,000$ people. $^{24}$ Age-specific incidence of asthma in patients aged 65 to 74 years was 103 cases/100,000 people. $^{24}$ A prospective study in a Tasmanian population demonstrated that $10.8 \%$ of patients who reported asthma, exhibited first symptoms of asthma in adulthood (no clear age cut-off for adulthood provided). ${ }^{5}$ The Russian registry for severe bronchial asthma (RSAR) contains data on the onset of the disease in 1791 patients (as of September 2019). If an age cut-off of $\geq 30$ years is considered in this study, $66 \%$ of patients can be diagnosed with LOA. ${ }^{30}$

It is evident from these reports that, irrespective of the geography evaluated or age cut-off used, LOA affects a considerable proportion of patients with asthma.

\section{Clinical Phenotypes of LOA}

Several clinical phenotypes of LOA have been described based on clinical presentation (allergic, non-allergic and occupational), underlying airway inflammation (eosinophilic and non-eosinophilic), severity and physiological parameters (Figure 1).

The Seinäjoki Adult Asthma Study, a 12-year followup study in patients with new-onset adult asthma identified five sub-phenotypes: nonrhinitic asthma, smoking asthma, female asthma, obesity-related asthma and early-onset atopic adult asthma. ${ }^{31}$ In a review by Hirano et al, LOA was classified into two phenotypes - Type 2-LOA or non-

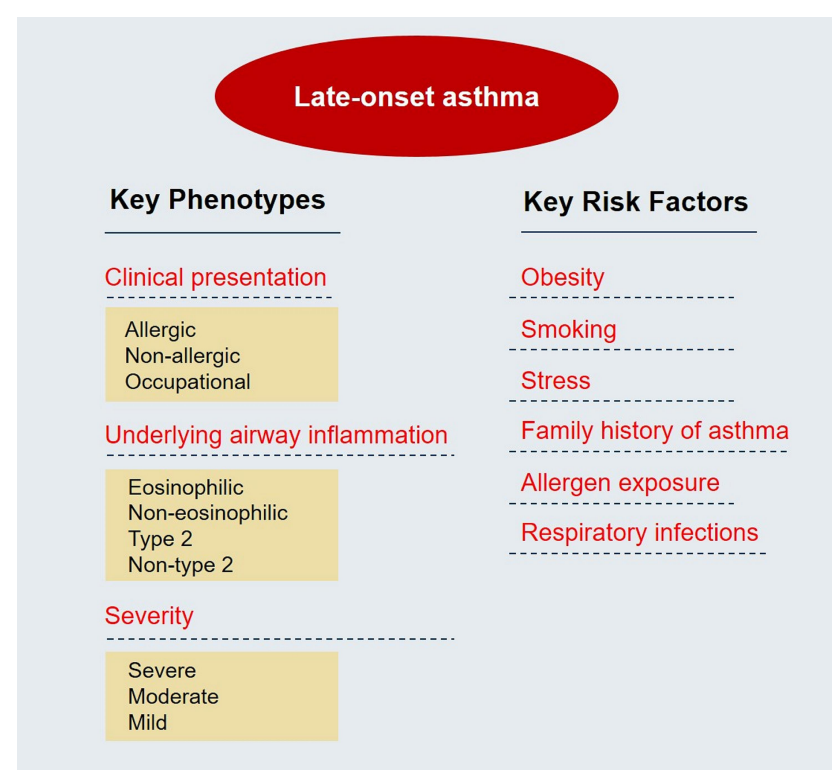

Figure I Key phenotypes and risk factors of late-onset asthma.

type 2 LOA. Type 2-LOA is associated with sinusitis, nasal polyps, and, sometimes, aspirin-exacerbated respiratory disease (AERD) appears to be equally common in males and females and is often severe from the onset. Non-Type 2-LOA is associated with female gender, obesity, smoking, and aging. ${ }^{32}$

In a study in 2013 by Amelink et al, patients with LOA were classified into three clusters. The first cluster consisted of patients with severe eosinophilic inflammationpredominant asthma and persistent airflow limitation despite high-intensity anti-inflammatory treatment, with relatively low symptom scores. The second cluster consisted of obese women with frequent symptoms, high healthcare utilization and low sputum eosinophils. The third cluster consisted of patients with mild-to-moderate, well-controlled asthma with normal lung function and low inflammatory markers. ${ }^{33}$

In a review article by Nijs et al, the following 4 phenotypes of LOA have been proposed: adult-onset obese female preponderant asthma; adult-onset nonatopic, inflammation-predominant phenotype with fixed airflow limitation; adult-onset mild asthma and smoking-related asthma. $^{3}$

Another important observation is the role of innate lymphoid cells group 2 (ILC2) in both early-onset and late-onset asthma phenotypes. It has been speculated that the activation of ILC2 $s$ in the absence of $\mathrm{T}$ cells and $\mathrm{B}$ cells is enough to induce asthma-like symptoms, and that ILC2s may play a role in early onset allergic asthma. ${ }^{34}$ 
Moreover, role of ILC2 has also been indicated in the LOA with nasal polyposis phenotype. ${ }^{8}$ ILC2s in both early-onset asthma and LOA with polyposis are regulated by epithelial-cell-derived thymic stromal lymphopoietin (TSLP), interleukin 25 (IL-25) and IL-33. ${ }^{34}$

It is worth to note that phenotypes of asthma may not always provide deep insights into the underlying disease process; therefore, endotypes have been proposed to indicate a subtype of a condition defined by a specific biologic mechanism. For example, LOA can be distinguished from early-onset asthma in the case of severe LOA hypereosinophilic asthma that is not thought to be Th2-driven in spite of marked peripheral and tissue eosinophilia and response to IL-5 antibody. ${ }^{35}$

The aforementioned publications suggest that LOA is not a single entity, but consists of distinct phenotypes some of which drastically differ in their clinical characteristics and prognosis. This implies that treatment strategies of LOA cannot be the same for all, and physicians should be mindful of the different presentations of the same condition.

\section{Clinical Characteristics and Risk Factors of LOA}

While genetic factors, early respiratory infections and environmental exposures are well-recognized risk factors for childhood asthma, risk factors associated with LOA asthma are not well documented (Figure 1).

The risk of asthma in adults is reported to be higher in obese patients (BMI $\geq 30$ ) when compared to nonobese patients. ${ }^{36}$ Some studies have suggested that obesity may lead to changes in the structure of the lung in patients with LOA. ${ }^{37,38}$ Women are more likely than men to develop asthma after the age of $20 .^{39,40}$ LOA mainly affects females with high body mass index (BMI). ${ }^{28,39,41}$ Furthermore, Ilmarinen et al reported that obese LOA patients experienced more exacerbations and respiratory-related hospital admissions compared to normal-weight patients during 12-year follow-up. ${ }^{42}$ In the Severe Asthma Research Program, obese patients with LOA showed increased respiratory symptoms, reduced lung function, lower $\operatorname{IgE}$ levels, and reduced fractional exhaled nitric oxide. ${ }^{43}$ Smoking has also been indicated to be correlated to LOA. A clear doseresponse association for exposure to tobacco and risk of new-onset asthma was observed in a multivariate analysis. In this study, smokers had an odds ratio (OR) of
2.05 with $1-10$ pack-years (95\% CI 0.99-4.27), an OR of 3.71 (95\% CI 1.77-7.78) in those with 11-20 packyears, and an OR of 5.05 (95\% CI 1.93-13.20) in those with $>21$ pack-years compared with never-smokers. ${ }^{44}$ In smokers with late-onset asthma, the risk of airway obstruction compared with never-smokers was higher. ${ }^{45}$ Coogan et al reported in a longitudinal study with $>14$ years of follow-up that both active and passive smokers exhibited an increased incidence of new adult-onset asthma (approximately 40\% and 20\%, respectively) versus non-smoking asthmatics. ${ }^{46}$ Stress has been shown to modulate and activate a number of biological pathways that may be involved in asthma pathophysiology. ${ }^{47}$ High versus low stress was found to be associated with a twoto three-fold higher risk of self-reported asthma incidence in several longitudinal population studies. ${ }^{48-50}$

Family history of asthma has been reported to be a stronger determinant of early-onset asthma when compared to LOA. ${ }^{51,52}$ However, Toren et al reported that a family history of asthma was also strongly associated [odds ratio (OR) $(95 \% \mathrm{CI}), 2.1(1.7-2.6)$ ] with LOA. $^{15}$ Furthermore, parental allergy and exposure to pets in childhood have been associated with increased risk of asthma development in adulthood. ${ }^{53}$

Respiratory infections may also play a role in LOA. A large population-based study that included a follow-up of 581,000 person-years showed that both upper and lower respiratory tract infections 12 months prior to the asthmaonset are strong determinants of LOA in the working population. ${ }^{54}$ LOA and severe asthma have also been associated with occupational exposures. ${ }^{55}$ Furthermore, it has been reported that occupational asthma-chronic obstructive pulmonary disease overlap is more common in patients with LOA. $^{56}$

In addition to having distinct risk factors, the clinical characteristics of LOA also are quite different from childhood-onset asthma. LOA commonly runs a much more severe course and is associated with poor prognosis, ${ }^{57}$ rapid decline in lung function ${ }^{58,59}$ and severe persistent airflow limitation. ${ }^{60,61}$ A cross-sectional analysis of 80 patients with severe asthma reported lower mean forced vital capacity (percent predicted) $[66 \pm 4$ vs $76 \pm 3]$ and mean forced expiratory volume in one second $\left(\mathrm{FEV}_{1}\right)$ (percent predicted) $[48 \pm 4$ vs $56 \pm 3]$ in patients with severe LOA versus patients with early-onset asthma. ${ }^{8}$ Compromised lung function in patients with LOA, despite shorter duration of illness, suggests that significant loss of lung function occurs at/or soon after the initial diagnosis. ${ }^{3}$ 
Patients with LOA are almost five times more likely to have persistent rather than intermittent asthma than patients with early-onset asthma. ${ }^{18}$ Although the incidence of asthma is highest in childhood, asthma deaths occur more commonly in older age groups. ${ }^{62}$

LOA is often associated with increased use of corticosteroids and short-acting $\beta_{2}$-agonists (SABA). ${ }^{23,63}$ A population-based study from Taiwan reported higher OR of SABA use and healthcare use in LOA (onset age of 26-50 years) versus early-onset asthma. ${ }^{23}$ Similarly, the results of a cluster analysis from the Severe Asthma Research Program reported higher use of healthcare resources in late-onset asthmatics with mean onset age of 42 years compared to other clusters. $^{60}$

\section{The Role of Allergy in LOA}

In addition to all the risk factors and comorbidities described in the previous section, we also reviewed the current literature to explore the role of allergy in the development of LOA. Although LOA has been conventionally thought to be non-allergic in nature, the published literature reveals that LOA is commonly associated with allergic comorbidities.

Allergic rhinitis is more prevalent in LOA compared to childhood-onset asthma. ${ }^{23} \mathrm{~A}$ strong association of nasal allergies with both early-onset asthma and LOA has been reported. ${ }^{16}$ A population-based study in Swedish population reporting high incidence rate of LOA showed a strong association between incidence of asthma and allergic comorbidities such as allergic rhinitis [OR $(95 \% \mathrm{CI}), 4.1$ (3.4-5.2)] and atopic dermatitis [OR (95\% CI), 1.4 (1.04-1.9)]. Among the patients reporting hay fever, the incidence of LOA was 2.7/1000 person-years. ${ }^{15}$ In an epidemiological study in 4173 subjects in Finland, in the age groups $0-9,10-19,20-29,30-39,40-49,50-59$ and 60-69 years, $70.4 \%, 62.0 \%, 58.3 \%, 52.5 \%, 37.7 \%, 19.2 \%$ and $33.3 \%$ of the new asthma cases, respectively, were classified as allergic. ${ }^{64}$

In addition to being associated with allergic comorbidities, patients with LOA also have elevated signs of immunoglobulin $\mathrm{E}$ (IgE) and show signs of atopy. ${ }^{65-67}$ In a study by Burrows et al, high levels of serum IgE were reported to be a strong predictor of LOA. Some of the common antigens and allergens that might induce increases in IgE include dust mite, mold exposure and superantigens such as Staphylococcus aureus. ${ }^{19,65-67}$ A population-based study in adults aged 21-63 years living in South Finland showed that the risk of asthma was related to the presence of visible mold and/or mold odor in the workplace (OR, 1.54; 95\% CI, 1.01-2.32). About $35.1 \%$ of asthma incidence amongst the exposed population was attributed to workplace mold exposure. Fungal (aspergillus, penicillium, alternaria) sensitization is associated with moderate asthma; however, this can progress to severe asthma if exposed to abnormally high fungal concentrations. ${ }^{68,69}$ In a study by Ariano et al, the most commonly found allergen was the dust mite species Dermatophagoides pteronyssinus (75\%). ${ }^{67}$ Another population-based study from St. Vincent and the Grenadines also reported that dust mite was the most common allergen in positive skin test with $66 \%$ reactivity. ${ }^{19}$

We examined different registries and population-based studies to evaluate the prevalence of allergic conditions with early- and late-onset asthma. The information obtained from these publications is summarized in Table 2. On examination of these data, it is evident that allergy is frequently associated with the LOA phenotype and plays a significant role in it.

\section{Conclusions}

Patients with LOA constitute a significant subset of the population suffering with asthma. LOA presents with clinical characteristics and risk factors, which are distinct from childhood-onset asthma. Despite this, our review reveals that there are some noticeable gaps in the understanding and management of this condition. Unfortunately, there seems to exist no consensus among the medical community about the exact age cut-off that defines LOA. Our review also reveals that, contrary to conventional thinking, patients with LOA are frequently allergic and have allergic comorbidities. These findings should help update existing management strategies with more treatment options and reduce systemic corticosteroid usage; nevertheless, there is a need to first clearly differentiate between different LOA phenotypes before applying the findings to treatment strategies.

In conclusion, there is an urgent need for the development of clinical practice guidelines that can provide more clarity on the definition and aspects of LOA, particularly its diagnosis and management. Furthermore, the association of allergy in LOA needs to be re-examined, so that clinicians can tailor their treatment strategies to ensure optimal outcome for these patients. 


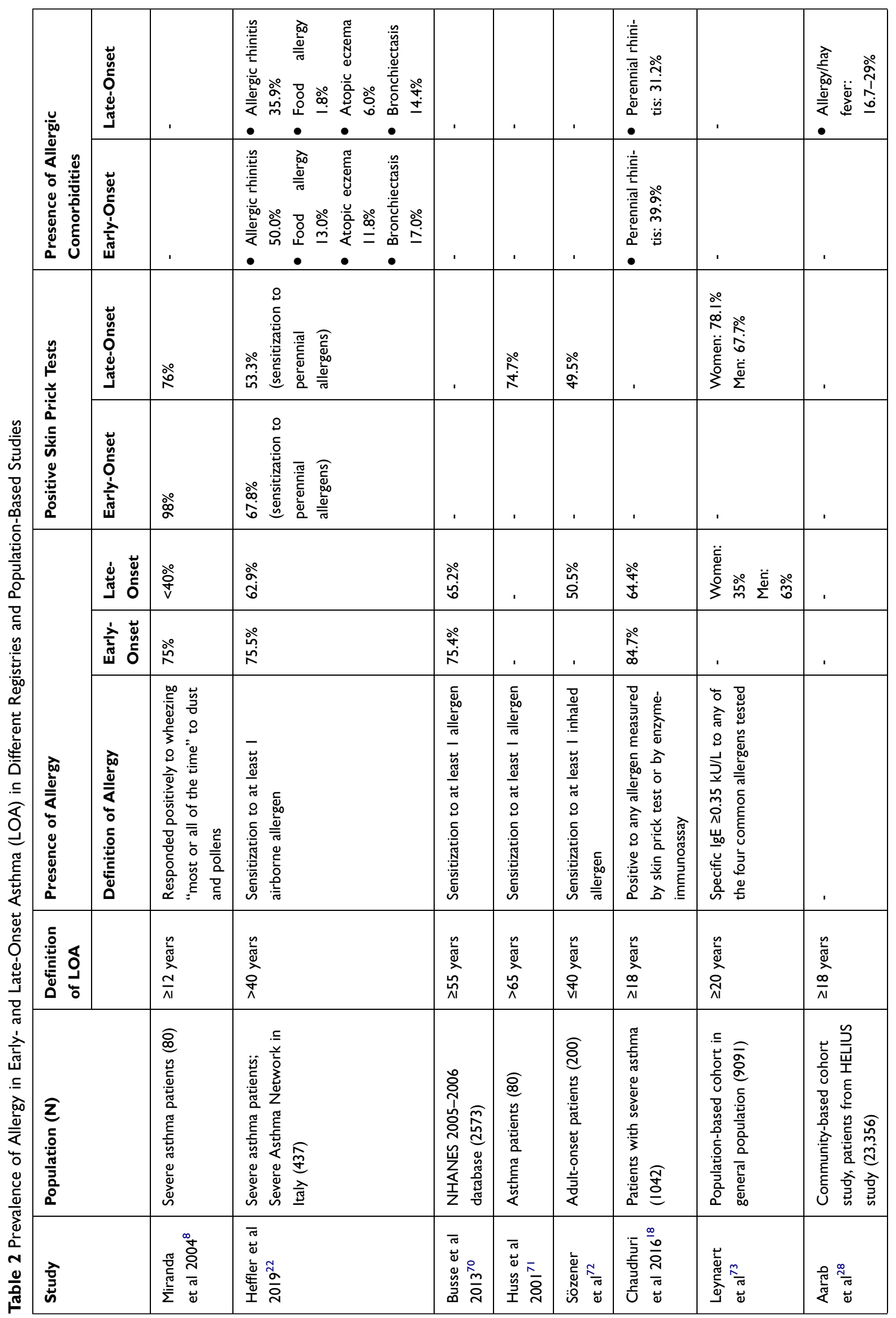




\begin{tabular}{|c|c|c|}
\hline 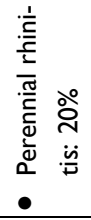 & 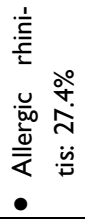 & \\
\hline 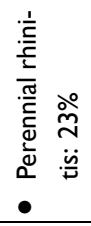 & 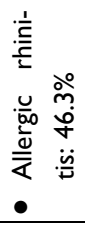 & ' \\
\hline ' & $\begin{array}{l}\text { ठ̊ } \\
\text { ホ }\end{array}$ & ' \\
\hline ' & $\frac{\stackrel{\circ}{m}}{\sigma}$ & ' \\
\hline ' & 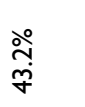 & ' \\
\hline ' & $\begin{array}{l}\stackrel{0}{ } \\
\text { †े } \\
\text { †े }\end{array}$ & $\frac{\stackrel{\circ}{\dot{\gamma}}}{\dot{\sigma}}$ \\
\hline & 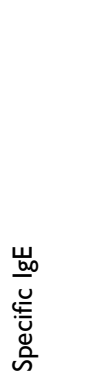 & 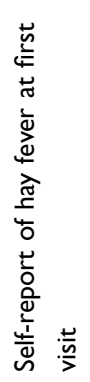 \\
\hline 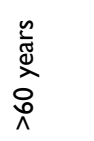 & 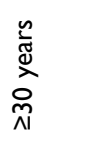 & 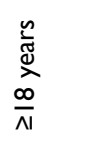 \\
\hline 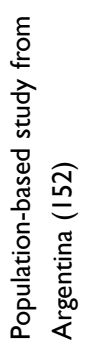 & 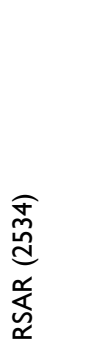 & 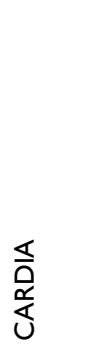 \\
\hline 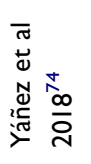 & 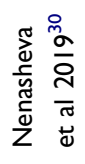 & 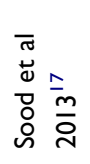 \\
\hline
\end{tabular}

\section{Abbreviations}

AERD, aspirin-exacerbated respiratory disease; EAACI, European Academy of Allergy and Clinical Immunology; $\mathrm{FEV}_{1}$, forced expiratory volume in one second; GINA, Global Initiative for Asthma; GA ${ }^{2}$ LEN, Global Allergy and Asthma Network of Excellence; HELIUS study, the Healthy Life in an Urban Setting study; ICS, inhaled corticosteroids; IgE, immunoglobulin E; LOA, late onset manuscript; RSAR, Russian registry for severe bronchial asthma; SABA, short-acting $\beta_{2}$-agonists.

\section{Consent for Publication}

Not applicable.

\section{Acknowledgments}

The authors thank Anupama Boddupalli and Rahul Lad (Novartis Healthcare Pvt. Ltd. India) for providing medical writing support/editorial support, which was funded by Novartis, in accordance with Good Publication Practice (GPP3) guidelines (http://www.ismpp.org/gpp3).

\section{Author Contributions}

All authors made substantial contributions to conception and design of this article; took part in drafting the article or revising it critically for important intellectual content; agreed to submit to the current journal; gave final approval of the version to be published; and agree to be accountable for all aspects of the work.

\section{Disclosure}

Dr. Quirce reports personal fees and non-financial support from GSK, personal fees and non-financial support from AstraZeneca, personal fees and non-financial support from Sanofi, personal fees and non-financial support from Novartis, personal fees and non-financial support from Mundipharma, personal fees and non-financial support from Teva, personal fees and non-financial support from Allergy Therapeutics, outside the submitted work. Dr. Heffler reports grants and personal fees from AstraZeneca, grants and personal fees from Novartis, grants and personal fees from Sanofi, personal fees from GSK, personal fees from Circassia, personal fees from Nestlè Purina, outside the submitted work. Dr. Nenasheva has nothing to disclose. Dr. Demoly reports grants from Stallergène Greer, grants from ALK, grants from AstraZeneca, grants from Bausch \& Lomb, grants from Thermo Fisher Scientific, personal 
fees from Sanofi-Regeneron, outside the submitted work. Dr. Menzies-Gow reports grants and personal fees from Astra Zeneca, personal fees from Glaxo SmithKline, personal fees from Novartis, personal fees and nonfinancial support from Teva, personal fees from Sanofi, personal fees from Vectura, personal fees and nonfinancial support from Boehringer Ingelheim, outside the submitted work. Ana Moreira-Jorges is an employee of Novartis. Dr. Nissen reports grants from Novartis, during the conduct of the study; is now employed by Roche, also reports grants from GSK, outside the submitted work. Dr Hanania has received personal fees for serving as an advisor or consultant to GSK, Astra Zeneca, Novartis, Sanofi/Regeneron and Mylan. His institution has received grant support for research on his behalf from GSK, Astra Zeneca, Novartis, Sanofi/ Regeneron, Boehringer Ingelheim and Gossamer Bio. The authors report no other conflicts of interest in this work.

\section{References}

1. Asthma 2020. Available from: https://www.who.int/news-room /q-a-detail/asthma. Accessed 18 June 2020.

2. Global Strategy for Asthma Management and Prevention. Global initiative for asthma. 2020. Available from: https://ginasthma.org/ gina-reports/. Accessed 18 June 2020.

3. de Nijs SB, Venekamp LN, Bel EH. Adult-onset asthma: is it really different? Eur Respir Rev. 2013;22(127):44-52. doi:10.1183/ 09059180.00007112

4. Dharmage SC, Perret JL, Custovic A. Epidemiology of asthma in children and adults. Front Pediatr. 2019;7:246. doi:10.3389/ fped.2019.00246

5. Jenkins MA, Hopper JL, Bowes G, Carlin JB, Flander LB, Giles GG. Factors in childhood as predictors of asthma in adult life. BMJ. 1994;309(6947):90-93. doi:10.1136/bmj.309.6947.90

6. Rackemann FM. A working classification of asthma. Am J Med. 1947;3(5):601-606. doi:10.1016/0002-9343(47)90204-0

7. Johansson SG, Hourihane JO, Bousquet J, et al. A revised nomenclature for allergy. An EAACI position statement from the EAACI nomenclature task force. Allergy. 2001;56(9):813-824. doi:10.1034/ j.1398-9995.2001.t01-1-00001.x

8. Miranda C, Busacker A, Balzar S, Trudeau J, Wenzel SE. Distinguishing severe asthma phenotypes: role of age at onset and eosinophilic inflammation. J Allergy Clin Immunol. 2004;113 (1):101-108. doi:10.1016/j.jaci.2003.10.041

9. Moffatt MF, Gut IG, Demenais F, et al., GABRIEL Consortium. A large-scale, consortium-based genomewide association study of asthma. $N$ Engl J Med. 2010;363(13):1211-1221. doi:10.1056/ NEJMoa0906312

10. Pividori M, Schoettler N, Nicolae DL, Ober C, Im HK. Shared and distinct genetic risk factors for childhood-onset and adult-onset asthma: genome-wide and transcriptome-wide studies. Respir Med. 2019;7(6):509-522.

11. Hansen S, Probst-Hensch N, Keidel D, et al. Gender differences in adult-onset asthma: results from the Swiss SAPALDIA cohort study. Eur Respir J. 2015;46(4):1011-1020. doi:10.1183/13993003.022782014
12. Wu TJ, Wu CF, Chen BY, Lee YL, Guo YL. Age of asthma onset and vulnerability to ambient air pollution: an observational population-based study of adults from Southern Taiwan. BMC Pulm Med. 2016;16(1):54. doi:10.1186/s12890-016-0218-0

13. Holguin F, Bleecker ER, Busse WW, et al. Obesity and asthma: an association modified by age of asthma onset. J Allergy Clin Immunol. 2011;127(6):1486-1493. doi:10.1016/j.jaci.2011.03.036

14. Jayashri Bhaskar ML, Georas S, Smith SM, Khurana S. Differences between early- and late-onset asthma; data from an asthma registry. Am J Respir Crit Care Med. 2013;187:A2325.

15. Toren K, Hermansson BA. Incidence rate of adult-onset asthma in relation to age, sex, atopy and smoking: a Swedish population-based study of 15813 adults. Int J Tuberc Lung Dis. 1999;3(3):192-197.

16. Jarvis D, Newson R, Lotvall $\mathrm{J}$, et al. Asthma in adults and its association with chronic rhinosinusitis: the GA2LEN survey in Europe. Allergy. 2012;67(1):91-98. doi:10.1111/j.1398-9995.2011. 02709.x

17. Sood A, Qualls C, Schuyler M, et al. Adult-onset asthma becomes the dominant phenotype among women by age 40 years. The longitudinal CARDIA study. Ann Am Thorac Soc. 2013;10(3):188-197. doi:10.1513/AnnalsATS.201212-115OC

18. Chaudhuri R, McSharry C, Heaney LG, et al. Effects of older age and age of asthma onset on clinical and inflammatory variables in severe refractory asthma. Respir Med. 2016;118:46-52. doi:10.1016/j. rmed.2016.07.005

19. Schwindt CD, Bacchus H, Leu SY, Tjoa T, Klebanova Y, Delfino RJ. Characterization of the asthmatic population of St. Vincent and the Grenadines: asthma severity levels and atopic sensitization. J Asthma. 2010;47(8):871-877. doi:10.3109/02770903.2010.506682

20. Bedolla-Barajas M, Morales-Romero J, Ramses-Bedolla-Pulido T, Fabiola-Garcia-Padilla L, Hernandez-Colin D. Associated markers for adult-onset allergic asthma. Iran $J$ Allergy Asthma Immunol. 2015;14(5):545-551.

21. Maio S, Baldacci S, Bresciani M, et al. RItA: the Italian severe/ uncontrolled asthma registry. Allergy. 2018;73(3):683-695. doi:10. 1111/all.13342

22. Heffler E, Blasi F, Latorre M, et al. The severe asthma network in Italy: findings and perspectives. J Allergy Clin Immunol Pract. 2019;7(5):1462-1468. doi:10.1016/j.jaip.2018.10.016

23. Wu TJ, Chen BY, Lee YL, Hsiue TR, Wu CF, Guo YL. Different severity and severity predictors in early-onset and late-onset asthma: a Taiwanese population-based study. Respiration. 2015;90 (5):384-392. doi:10.1159/000439310

24. Bauer BA, Reed CE, Yunginger JW, Wollan PC, Silverstein MD. Incidence and outcomes of asthma in the elderly. A population-based study in Rochester, Minnesota. Chest. 1997;111(2):303-310. doi:10. 1378/chest.111.2.303

25. Gillman A, Douglass JA. Asthma in the elderly. Asia Pac Allergy. 2012;2(2):101-108. doi:10.5415/apallergy.2012.2.2.101

26. Ariano R, Panzani RC. Late onset asthma in the elderly and its relationship with atopy. Eur Ann Allergy Clin Immunol. 2012;44 (2):35-41.

27. Gibson PG, McDonald VM, Marks GB. Asthma in older adults. Lancet. 2010;376(9743):803-813. doi:10.1016/S0140-6736(10) 61087-2

28. Aarab R, Vijverberg SJH, Prins M, et al. Prevalence of and factors associated with adult-onset asthma in different ethnic groups: the HELIUS study. Respir Med. 2019;150:113-119. doi:10.1016/j. rmed.2019.02.018

29. Casas X, Monso E, Orpella X, et al. [Incidence and characteristics of adult-onset asthma]. Arch Bronconeumol. 2008;44(9):471-477. doi:10.1016/S0300-2896(08)72116-1. Spanish.

30. Nenasheva N, Belevsky A, Kravchenko N, et al. Late breaking abstract - preliminary analysis of the data of patients with severe bronchial asthma included in the Russian National Register of Severe Asthma (RSAR. Eur Respir J. 2019;54:PA4261. 
31. Ilmarinen P, Tuomisto LE, Niemela O, Tommola M, Haanpaa J, Kankaanranta H. Cluster analysis on longitudinal data of patients with adult-onset asthma. J Allergy Clin Immunol Pract. 2017;5 (4):967-978. (). doi:10.1016/j.jaip.2017.01.027

32. Hirano T, Matsunaga K. Late-onset asthma: current perspectives. J Asthma Allergy. 2018;11:19-27. doi:10.2147/JAA.S125948

33. Amelink M, de Nijs SB, de Groot JC, et al. Three phenotypes of adult-onset asthma. Allergy. 2013;68(5):674-680. doi:10.1111/ all. 12136

34. Ozyigit LP, Morita H, Akdis M. Innate lymphocyte cells in asthma phenotypes. Clin Transl Allergy. 2015;5:23. doi:10.1186/s13601-0150068-5

35. Agache I, Sugita K, Morita H, et al. The complex type 2 endotype in allergy and asthma: from laboratory to bedside. Curr Allergy Asthma Rep. 2015;15:29. doi:10.1007/s11882-015-0529-x

36. Huovinen E, Kaprio J, Koskenvuo M. Factors associated to lifestyle and risk of adult onset asthma. Respir Med. 2003;97(3):273-280. doi:10.1053/rmed.2003.1419

37. Mahadev S, Salome CM, Berend N, King GG. The effect of low lung volume on airway function in obesity. Respir Physiol Neurobiol. 2013;188(2):192-199. doi:10.1016/j.resp.2013.05.021

38. Al-Alwan A, Bates JH, Chapman DG, et al. The nonallergic asthma of obesity. A matter of distal lung compliance. Am J Respir Crit Care Med. 2014;189(12):1494-1502. doi:10.1164/rccm.201401-0178OC

39. Tan DJ, Walters EH, Perret JL, et al. Age-of-asthma onset as a determinant of different asthma phenotypes in adults: a systematic review and meta-analysis of the literature. Expert Rev Respir Med. 2015;9(1):109-123. doi:10.1586/17476348.2015.1000311

40. Fuchs O, Bahmer T, Rabe KF, von Mutius E. Asthma transition from childhood into adulthood. Lancet Respir Med. 2017;5(3):224-234. doi:10.1016/S2213-2600(16)30187-4

41. Ilmarinen P, Tuomisto LE, Kankaanranta H. Phenotypes, risk factors, and mechanisms of adult-onset asthma. Mediators Inflamm. 2015;2015:514868. doi:10.1155/2015/514868

42. Ilmarinen P, Pardo A, Tuomisto LE, et al. Long-term prognosis of new adult-onset asthma in obese patients. Eur Respir J. 2020; 8:2001209. doi:10.1183/13993003.01209-2020

43. Holguin F, Comhair SAA, Hazen SL, et al. An association between L-arginine/asymmetric dimethyl arginine balance, obesity, and the age of asthma onset phenotype. Am J Respir Crit Care Med. 2013;187:153-159. doi:10.1164/rccm.201207-12700C

44. Polosa R, Knoke JD, Russo C, et al. Cigarette smoking is associated with a greater risk of incident asthma in allergic rhinitis. $J$ Allergy Clin Immunol. 2008;121(6):1428-1434. doi:10.1016/j.jaci.2008.02. 041

45. Aanerud M, Carsin AE, Sunyer J, et al. Interaction between asthma and smoking increases the risk of adult airway obstruction. Eur Respir J. 2015;45(3):635-43.11. doi:10.1183/09031936.00055514

46. Coogan PF, Castro-Webb N, Yu J, O'Connor GT, Palmer JR, Rosenberg L. Active and passive smoking and the incidence of asthma in the Black Women's Health Study. Am J Respir Crit Care Med. 2015;191(2):168-176. doi:10.1164/rccm.201406-1108OC

47. Vink NM, Boezen HM, Postma DS, Rosmalen JG. Basal or stress-induced cortisol and asthma development: the TRAILS study. Eur Respir J. 2013;41(4):846-852. doi:10.1183/09031936.00021212

48. Lietzen R, Virtanen P, Kivimaki M, Sillanmaki L, Vahtera J, Koskenvuo M. Stressful life events and the onset of asthma. Eur Respir J. 2011;37(6):1360-1365. doi:10.1183/09031936.00164609

49. Loerbroks A, Gadinger MC, Bosch JA, Sturmer T, Amelang M. Work-related stress, inability to relax after work and risk of adult asthma: a population-based cohort study. Allergy. 2010;65 (10):1298-1305. doi:10.1111/j.1398-9995.2010.02375.x

50. Rod NH, Kristensen TS, Lange P, Prescott E, Diderichsen F. Perceived stress and risk of adult-onset asthma and other atopic disorders: a longitudinal cohort study. Allergy. 2012;67 (11):1408-1414. doi:10.1111/j.1398-9995.2012.02882.x.
51. Paaso EM, Jaakkola MS, Rantala AK, Hugg TT, Jaakkola JJ. Allergic diseases and asthma in the family predict the persistence and onset-age of asthma: a prospective cohort study. Respir Res. 2014;15:152. doi:10.1186/s12931-014-0152-8

52. London SJ, James Gauderman W, Avol E, Rappaport EB, Peters JM. Family history and the risk of early-onset persistent, early-onset transient, and late-onset asthma. Epidemiology. 2001;12(5):577-583. doi:10.1097/00001648-200109000-00019

53. Jaakkola JJ, Jaakkola N, Piipari R, Jaakkola MS. Pets, parental atopy, and asthma in adults. $J$ Allergy Clin Immunol. 2002;109(5):784-788. doi:10.1067/mai.2002.123870

54. Rantala A, Jaakkola JJ, Jaakkola MS. Respiratory infections precede adult-onset asthma. PLoS One. 2011;6(12):e27912. doi:10.1371/journal.pone. 0027912

55. Henneberger PK, Mirabelli MC, Kogevinas M, et al. The occupational contribution to severe exacerbation of asthma. Eur Respir J. 2010;36(4):743-750. doi:10.1183/09031936.00135109

56. Tarlo SM, Quirce S. Impact of identification of clinical phenotypes in occupational asthma. J Allergy Clin Immunol Pract. 2020;8 (10):3277-3282. doi:10.1016/j.jaip.2020.06.003

57. de Marco R, Locatelli F, Cerveri I, Bugiani M, Marinoni A, Giammanco G, de Marco Rea. Incidence and remission of asthma: a retrospective study on the natural history of asthma in Italy. $J$ Allergy Clin Immunol. 2002;10(2):228-235. doi:10.1067/mai.2002.125600

58. Amelink M, de Nijs SB, Berger M, et al. Non-atopic males with adult onset asthma are at risk of persistent airflow limitation. Clin Exp Allergy. 2012;42(5):769-774. doi:10.1111/j.1365-2222.2012.03977.x

59. Ulrik CS, Lange P. Decline of lung function in adults with bronchial asthma. Am J Respir Crit Care Med. 1994;150(3):629-634. doi:10.1164/ajrccm.150.3.8087330

60. Moore WC, Meyers DA, Wenzel SE, et al. Identification of asthma phenotypes using cluster analysis in the Severe Asthma Research Program. Am J Respir Crit Care Med. 2010;181(4):315-323. doi:10.1164/rccm.200906-0896OC

61. Jenkins HA, Cherniack R, Szefler SJ, Covar R, Gelfand EW, Spahn JD. A comparison of the clinical characteristics of children and adults with severe asthma. Chest. 2003;124(4):1318-1324. doi:10.1378/chest.124.4.1318

62. Asthma key facts. World Health Organization website. Available from: https://www.who.int/en/news-room/fact-sheets/detail/asthma. Accessed 15 September 2020.

63. Quadrelli SA, Roncoroni AJ. Is asthma in the elderly really different? Respiration. 1998;65(5):347-353. doi:10.1159/000029294

64. Pakkasela J, Ilmarinen P, Honkamaki J, et al. Age-specific incidence of allergic and non-allergic asthma. BMC Pulm Med. 2020;20(1):9. doi:10.1186/s12890-019-1040-2

65. Barnes PJ. Intrinsic asthma: not so different from allergic asthma but driven by superantigens? Clin Exp Allergy. 2009;39(8):1145-1151. doi:10.1111/j.1365-2222.2009.03298.x

66. de Groot JC, Ten Brinke A, Bel EH. Management of the patient with eosinophilic asthma: a new era begins. ERJ Open Res. 2015;1:1. doi:10.1183/23120541.00024-2015

67. Ariano R, Panzani RC, Augeri G. Late onset asthma clinical and immunological data: importance of allergy. $J$ Investig Allergol Clin Immunol. 1998;8(1):35-41.

68. Denning DW, Pashley C, Hartl D, et al. Fungal allergy in asthma-state of the art and research needs. Clin Transl Allergy. 2014;4:14. doi:10.1186/2045-7022-4-14

69. Denning DW, O'Driscoll BR, Hogaboam CM, Bowyer P, Niven RM. The link between fungi and severe asthma: a summary of the evidence. Eur Respir J. 2006;27(3):615-626. doi:10.1183/09031936.06.00074705

70. Busse PJ, Cohn RD, Salo PM, Zeldin DC. Characteristics of allergic sensitization among asthmatic adults older than 55 years: results from the National Health and Nutrition Examination Survey, 2005-2006. Ann Allergy Asthma Immunol. 2013;110(4):247-252. doi:10.1016/j. anai.2013.01.016 
71. Huss K, Naumann PL, Mason PJ, et al. Asthma severity, atopic status, allergen exposure and quality of life in elderly persons. Ann Allergy Asthma Immunol. 2001;86(5):524-530. doi:10.1016/S10811206(10)62900-6

72. Sozener ZC, Aydin O, Mungan D, Misirligil Z. Prognosis of adult asthma: a 7-year follow-up study. Ann Allergy Asthma Immunol. 2015;114(5):370-373. doi:10.1016/j.anai.2015. 02.010
73. Leynaert B, Sunyer J, Garcia-Esteban R, et al. Gender differences in prevalence, diagnosis and incidence of allergic and non-allergic asthma: a population-based cohort. Thorax. 2012;67(7):625-631. doi:10.1136/thoraxjnl-2011-201249

74. Yáñez A, Soria M, De Barayazarra S, et al. Clinical characteristics and comorbidities of elderly asthmatics who attend allergy clinics. Asthma Res Pract. 2018;4:5. doi:10.1186/s40733-018-0041-x

\section{Publish your work in this journal}

The Journal of Asthma and Allergy is an international, peer-reviewed open-access journal publishing original research, reports, editorials and commentaries on the following topics: Asthma; Pulmonary physiology; Asthma related clinical health; Clinical immunology and the immunological basis of disease; Pharmacological interventions and new therapies. The manuscript management system is completely online and includes a very quick and fair peer-review system, which is all easy to use. Visit http://www.dovepress.com/testimonials.php to read real quotes from published authors. 